Gut, 1983, 24, 692-701

Alimentary tract and pancreas

\title{
Immunoregulatory function of human intestinal mucosa lymphoid cells: evidence for enhanced suppressor cell activity in inflammatory bowel disease
}

\author{
C FIOCCHI, K R YOUNGMAN, AND R G FARMER \\ From the Departments of Molecular and Cellular Biology, Division of Research, and Gastroenterology \\ Division of Medicine, Cleveland Clinic Foundation, Cleveland, Ohio, USA
}

\begin{abstract}
SUMmaRY Abnormalities in immune regulation at the gut level may be relevant to the pathogenesis of inflammatory bowel disease, but little is known about the immunoregulatory properties of intestinal mononuclear cells. Therefore, we wished to see if lymphoid cells derived from the lamina propria of surgically resected bowel specimens have any modulatory effect upon the immune response of peripheral blood mononuclear cells from patients with ulcerative colitis or Crohn's disease. When autologous peripheral blood and intestinal lamina propria lymphoid cells were mixed at different ratios and cultured in the presence of phytohaemagglutinin, we were able to show that intestinal mononuclear cells had the capacity to modify the mitogenic response of the cultured cells. These intestinal immunoregulatory cells, when obtained from mucosa affected by inflammatory bowel disease, express a significantly enhanced suppressor cell activity as compared with those from non-inflamed control mucosa. Such suppressor cell activity varies with cell concentration and requires cell proliferation, but it is independent of anatomical origin (small $v s$ large bowel), type of inflammatory bowel disease (ulcerative colitis $v s$ Crohn's disease) or immunosuppressive therapy. These findings point to an important functional difference between inflammatory bowel disease and control intestinal mucosa mononuclear cells. The enhanced suppressor activity of lamina propria mononuclear cells may be associated with impairment of cell-mediated immunity at the gut level. This may be related to the pathogenesis of inflammatory bowel disease by leading to defective intestinal immune regulatory events, which may not be detectable at the peripheral level.
\end{abstract}

The development of methods for obtaining functionally viable human intestinal mucosa mononuclear cells ${ }^{1-3}$ has stimulated a renewed interest in the study of immune events occurring in inflammatory bowel disease (IBD). By evaluating the immunological properties of the lymphoid cells directly involved in the gut inflammatory process of patients with ulcerative colitis (UC) or Crohn's disease (CD), new information could be obtained that would shed some light on the pathogenesis of these chronic intestinal diseases.

Mononuclear cells from human intestinal lamina propria (LPL) have been shown to differ in cellular

Address for correspondence: Claudio Fiocchi, MD, Research Division. Cleveland Clinic Foundation. 9500 Euclid Avenue. Cleveland, Ohio, 44106. USA.

Received for publication 4 October 1982 composition and functional properties from those circulating in the peripheral blood (PBL) ${ }^{1-8}$ suggesting that they constitute a distinct subpopulation of immune competent cells with unique characteristics. ${ }^{9}$ Surprisingly, when lamina propria lymphocytes obtained from inflammatory bowel disease intestine are compared with those derived from histologically normal, non-inflammatory bowel disease specimens, more similarities than differences have been detected thus far. The proportion of $\mathrm{T}$ and $\mathrm{B}$ cells, and macrophages (MØ) are similar, ${ }^{256}$ the proliferative responses to polyclonal mitogens are generally comparable, ${ }^{78}$ neither effect cell-mediated lympholysis after an allogeneic mixed leucocyte reaction, and even the cytotoxic properties are remarkably similar. ${ }^{6}{ }^{10}{ }^{12}$ Differences between control and inflammatory bowel disease 692 
lamina propria lymphocytes have been found only in an enhanced capacity of the latter for synthesising $\mathrm{IgG}^{4}$ and proliferating in response to some bacterial antigens. ${ }^{8}$

It is difficult to conceive that more significant functional differences do not exist between mononuclear cells from inflammatory bowel disease affected and histologically normal intestinal mucosa. Most likely success in detecting such differences depends on the choice of an appropriate assay system or a relevant target for their expression. The chronicity of the inflammatory process in ulcerative colitis and -Crohn's disease suggests that some abnormalities of immune regulation are present at the gut mucosal level. Immunoregulatory properties of lamina propria lymphocytes have been only partially explored. Preliminary experiments in animals suggest that intestinal mononuclear cells may modulate the immune response of lymphoid cells from other organs, ${ }^{13}$ while Goodacre and Bienenstock recently reported reduced suppressor cell activity in the intestinal mucosa of Crohn's disease patients. ${ }^{14}$

The present study was undertaken to (1) further investigate the immunoregulatory function of human lamina propria lymphocytes over the systemic immune response by studying gut mucosal lymphoid cells derived from a large number of specimens affected by ulcerative colitis, Crohn's disease, and other intestinal pathological conditions, and (2) explore the influence of anatomical origin (small vs large bowel), type of inflammatory bowel disease (ulcerative colitis vs Crohn's disease), and immunosuppressive therapy on lamina propria lymphocytes suppressor cell activity.

\section{Methods}

PATIENTS

Patients who underwent bowel resection at the Cleveland Clinic constituted the source of both peripheral blood and lamina propria lymphocytes. They were divided into two groups. The first was formed by eight female and 17 male patients (aged 34-82 years) with carcinoma of the large bowel (CA; $n=20)$, diverticulosis $(n=3)$, benign colonic polyp $(n=1)$, and sigmoid volvulus $(n=1)$. The second group was formed by 11 female and 17 male patients (aged 13-54 years) with Crohn's disease $(n=18 ; 11$ on corticosteroids) and ulcerative colitis $(n=10$; six on corticosteroids). Diagnoses were established by clinical, radiological, and histological criteria. No significant nutritional deficiencies were present in the patients at the time of surgery. The project was approved by the Committee for Clinical Research Projects of the Cleveland Clinic Foundation (1980).
LYMPHOID CELLS

Peripheral blood mononuclear cells Heparinised venous blood was obtained during removal of the surgical specimen. Peripheral blood lymphocytes were isolated over a Ficoll-Hypaque gradient, washed and suspended in RPMI-1640 with added L-glutamine, HEPES buffer, penicillin, streptomycin, gentamycin, and $10 \%$ pooled, heat inactivated human AB serum (HABS).

Lamina propria mononuclear cells The method used to isolate lamina propria lymphocytes is a modification of the original technique of Bull and Bookman $^{1}$ and has been previously described in detail. ${ }^{3}$ Briefly, the dissected intestinal mucosa is freed of mucus and epithelial cells in sequential steps with dithiothreitol and EDTA; then digested with collagenase and deoxyribonuclease, after which the crude cell suspension is purified over a FicollHypaque gradient. The final culture medium was the same as described for peripheral blood lymphocytes. Control lamina propria lymphocytes were obtained from 22 large bowel and seven small bowel specimens from the first group of patients; ulcerative colitis and Crohn's disease lamina propria lymphocytes were obtained from 14 large bowel and 14 small bowel specimens from the second group of patients.

CELL SURFACE MARKERS CHARACTERISATION Immunofluorescent staining of lymphocytes surface immunoglobulin Lamina propria lymphocytes were washed and suspended in calcium and magnesium free Hank's balanced salt solution (CMF-HBSS), at $1 \times 10^{6} / \mathrm{ml}$. Mononuclear cells contained in $1 \mathrm{ml}$ cell suspension were pelleted and resuspended in one or two drops of fluorescein labelled antihuman polyvalent goat immunoglobulin (Meloy Laboratories Inc, Springfield, Virginia), which has been diluted 10 times. After 20 minutes of incubation on ice, the cells were washed twice with Veronal buffered saline (VBS) and resuspended. One drop of the lamina propria lymphocytes suspension was then placed on a slide, covered and examined under a fluorescent microscope.

Fc receptor quantitation Lamina propria lymphocytes were washed and suspended in CMF-HBSS at $1 \times 10^{6} / \mathrm{ml}$. Mononuclear cells contained in $2 \mathrm{ml}$ cell suspension were pelleted and mixed with $10 \mu \mathrm{l}$ of heat aggregated IgG (reconstituted from lyophilised human IgG; Miles Laboratories, Elkhart, Indiana). The cells were incubated at room temperature for 30 minutes and washed twice with Veronal buffered saline containing $0.2 \%$ sodium azide. The pelleted cells were then mixed with $10 \mu$ l fluorescein conjugated antihuman $\operatorname{IgG}\left(\mathrm{F}\left(\mathrm{ab}^{\prime}\right)_{2}\right.$ fragment; Kallestad, Chaska, Minnesota) and incubated on 
ice. After 30 minutes, the lamina propria lymphocytes were washed in Veronal buffered saline and resuspended for counting under a fluorescent microscope.

Analysis by monoclonal antibody. This was carried out using a modification of the method described by Kung et al. ${ }^{15}$ Lamina propria lymphocytes were washed and suspended in CMF-HBSS at $5 \times 10^{6} / \mathrm{ml}$. Mononuclear cells contained in $200 \mu \mathrm{l}$ cell suspension were mixed with $5 \mu \mathrm{l}$ reconstituted OKT3 monoclonal antibody (Ortho Pharmaceutical Corp, Raritan, New Jersey) and incubated on ice. After 30 minutes, the cells were washed twice in Veronal buffered saline and suspended in $100 \mu \mathrm{l}$ fluorescein labelled goat anti-mouse immunoglobulin (Meloy). The cells were incubated for $\mathbf{3 0}$ minutes, washed, resuspended and counted in a fluorescence-activated cell sorter (FACS II).

MITOMYCIN C AND RADIATION TREATMENT OF

LAMINA PROPRIA LYMPHOCYTES

To inhibit cell proliferation, $5-7 \times 10^{6}$ cells were incubated in $1 \mathrm{ml}$ volume of culture medium containing $40 \mu \mathrm{g} / \mathrm{ml}$ mitomycin C (ICN Pharmaceuticals, Cleveland, Ohio) for 45 minutes, with agitation every 15 minutes. At the end of incubation, the cells were washed three times in CMF-HBSS and suspended in the final culture medium. Alternatively, lamina propria lymphocytes were exposed to 1500 rads using a Phillips RT 100 $\mathrm{x}$-ray generator.

\section{CELL MIXING EXPERIMENTS}

To investigate if lamina propria lymphocytes have any modulatory effects in the presence of autologous peripheral blood lymphocytes responding to a polyclonal mitogen, cell mixing experiments were performed as follows. One hundreth millilitres of culture medium containing $1 \times 10^{5}$ peripheral blood lymphocytes was mixed in triplicate wells of microtitre plates (NUNC, Denmark) with equal volumes containing increasing concentrations of untreated, mitomycin $C$ treated, or irradiated autologous lamina propria lymphocytes. This resulted in lamina propria lymphocytes to peripheral blood lymphocytes ratios (LPL/PBL) of $0.5,1$, and 2 , the final concentration of lamina propria lymphocytes in the wells being respectively $0 \cdot 25,0.5$, and $1 \times 10^{6} / \mathrm{ml}$. An optimal amount $(10$ $\mu \mathrm{l} / \mathrm{ml}$ ) of phytohaemagglutinin (PHA) (Difco Laboratories, Detroit, Michigan) was then added to each well to obtain maximal stimulatory effect. ${ }^{8}$ Control experiments consisted of the same amount of peripheral blood lymphocytes and lamina propria lymphocytes, cultured alone in the presence and absence of phytohaemagglutinin, in $0.2 \mathrm{ml}$ of medium. All cell cultures were incubated at $37^{\circ} \mathrm{C}$ in a water saturated atmosphere with $5 \% \mathrm{CO}_{2}$ for 72 hours. This incubation period allows maximal proliferation of lamina propria lymphocytes and peripheral blood lymphocytes, as previously determined. ${ }^{8}$ Six hours before harvesting, $1 \mu \mathrm{Ci}$ tritiated $\left({ }^{3} \mathrm{H}\right)$-thymidine (specific activity $3 \mathrm{Ci} / \mathrm{mmol}$; Schwartz/Mann, Orangeburg, New York) was added to each well. Cells were harvested using a semi-automatic harvester (MASHII; Microbiological Associates, Bethesda, Maryland) and ${ }^{3} \mathrm{H}$-thymidine uptake was recorded as counts per minute (CPM) on a liquid scintillation system using a toluene and PPO-POPOP (Omnifluor; New England Nuclear, Boston, Massachusetts).

It was assumed that if no interaction existed between peripheral blood lymphocytes and lamina propria lymphocytes, while they were proliferating in response to phytohaemagglutinin, the final expected number of counts per minute for each mixing experiment would be the sum of the counts per minute by each individual set of cells used in each mixture. Variation from the expected response $(100 \%)$ was calculated dividing the observed response by the expected response, $\times 100$, as illustrated by the following formula:

$\%$ variation $=$

$$
\begin{gathered}
\frac{\mathrm{CPM}(\mathrm{PBL}+\mathrm{LPL}+\mathrm{PHA})}{\mathrm{CPM}(\mathrm{PBL}+\mathrm{PHA})+\mathrm{CPM}(\mathrm{LPL}+\mathrm{PHA})} \times 100 \\
+ \text { CPM (PBL + LPL) }
\end{gathered}
$$

Values $>100 \%$ and $<100 \%$ indicated respectively enhancement $(+)$ and suppression $(-)$ of the expected total proliferative response to phytohaemagglutinin.

\section{CONTROLS FOR CELL MIXING EXPERIMENTS}

To ensure that the percentage of variation obtained in the cell mixing experiments was not secondary to culture conditions, but was dependent on the immunological properties of the cells involved, three types of controls were performed.

To investigate crowding effect, inflammatory bowel disease, carcinoma, and normal volunteers peripheral blood lymphocytes $(n=6)$ were cultured in the presence of irradiated autologous peripheral blood lymphocytes in the same concentrations used for lamina propria lymphocytes.

To rule out defective proliferation as a result of inadequate quantities of mitogen, the final concentration of phytohaemagglutinin was doubled in some mixing experiments, maintaining the same number of cells in the cultures.

To investigate if the final proliferative responses were influenced by variability in the number of dead cells in the cell mixtures, two parallel cultures were prepared in some experiments. At the end of the 
incubation period, one culture was harvested to determine ${ }^{3} \mathrm{H}$-thymidine uptake, while the other was used to determine cell viability by the trypan blue exclusion method.

ANALYSIS OF DATA

Unless otherwise stated, all experimental values are expressed as the mean plus or minus standard error $( \pm$ SEM). Statistical analyses were performed by the Student's $t$ test and by linear regression analysis.

\section{Results}

CELL MARKERS CHARACTERISATION

Cell marker characteristics of lamina propria lymphocytes are summarised in Table 1 . Control lamina propria lymphocytes showed some differences from inflammatory bowel disease lamina propria lymphocytes in the percentages of $\mathrm{Fc}$ positive and null cells, but both populations contained similar proportions of $\mathrm{T}$ and $\mathrm{B}$ cells and macrophages.

\section{CELL MIXING EXPERIMENTS}

Proliferative responses of peripheral blood lymphocytes and lamina propria lymphocytes from patients with carcinoma were not different from those with non-malignant diseases, therefore results were grouped as controls. Similarly, proliferative responses from ulcerative colitis and Crohn's disease mononuclear cells were grouped as inflammatory bowel disease. Comparative results of the mixed cell cultures between controls and inflammatory bowel disease are illustrated in Table 2 . The unstimulated combined peripheral blood lymphocytes and lamina propria lymphocytes averaged 2000 counts per minute, did not exceed 7000 counts per minute, and represented 0.2 to $1.3 \%$ of the formula's denominator.

The percentages of variation of the expected phytohaemagglutinin-induced proliferative response between control and inflammatory bowel disease lamina propria lymphocytes were significantly different (Table 3). The effect was dependent on cell concentration, varying from enhancement to inhibition as the proportion of intestinal lymphoid cells increased. When the inflammatory bowel disease group was broken down into ulcerative colitis and Crohn's disease (Figure) and these compared with controls, significant differences were also observed $(\mathrm{p}<0.25 v s<0.005$ at lamina propria lymphocytes/peripheral blood lymphocytes ratio of $0.5 ; \mathrm{p}<0.05$ vs $<0.025$ at $1 ; \mathrm{p}<0.005$ vs $<0.001$ at 2 ; respectively for ulcerative colitis and Crohn's disease).

Within the inflammatory bowel disease group, no statistically significant differences in suppression were observed by comparing lamina propria lymphocytes obtained from ulcerative colitis and Crohn's disease patients (Table 3). The same was true for corticosteroid treated $v s$ untreated patients (Table 3).

Finally, when colonic lamina propria lymphocytes were compared with ileal lamina propria lymphocytes, no differences were noticed, except for controls at lamina propria lymphocytes/peripheral blood lymphocytes ratio of one (Table 3 ). This is likely to be secondary to the smaller number of experiments performed with small bowel cells, rather than a true difference. Indeed, when mucosa was obtained from colon and ileum of the same patient (four cases of caecal carcinoma), lamina propria lymphocytes from these two anatomically distinct segments of the intestine behaved similarly to each other in the cell mixing experiments.

The proliferative assays were quite reproducible during the time taken to complete the study. Counts per minute values from randomly selected groups of patients did not show any significant variation when tested by analysis of variance $(f=0 \cdot 324, p=0.726)$. Some variability of the results was observed within the control and inflammatory bowel disease groups, possibly on the basis of diverse clinical parameters. The large number of collected specimens, however, confirmed the consistency of the encountered differences.

\section{EFFECT OF MITOMYCIN C TREATMENT AND IRRADIATION}

The results of the cell mixing experiments suggested that an enhanced suppressor cell activity is present within the lymphoid cell population of the inflam-

Table 1 Markers of intestinal lamina propria mononuclear cells*

\begin{tabular}{lllllllr}
\hline LPL source & $(n)$ & OKT3 & $E^{+}$ & $S I g^{+}$ & $F^{+}$ & Nullt & $\alpha N A E^{+} \ddagger$ \\
\hline Controls & $(8)$ & $52 \pm 5 \cdot 9$ & $53 \pm 3 \cdot 2$ & $20 \pm 3 \cdot 5$ & $7 \pm 0 \cdot 7$ & $11 \pm 3 \cdot 8$ & $9 \pm 3 \cdot 7$ \\
IBD & $(5)$ & $59 \pm 3 \cdot 9$ & $50 \pm 10$ & $15 \pm 1 \cdot 5$ & $2 \pm 0 \cdot 5$ & $21 \pm 6 \cdot 6$ & $12 \pm 8 \cdot 5$ \\
\hline
\end{tabular}

* Numbers represent percentage values.

$\dagger$ Null cells are $\mathrm{E}^{-}, \mathrm{SIg}^{-}, \mathrm{Fc}^{-}$, and $\alpha \mathrm{NAE}^{-}$

$\ddagger \alpha \mathrm{NAE}^{+}$cells are defined by the presence of diffuse, coarse cytoplasmic granules. 
Table 2 Variation of the $P H A$-induced proliferative response in cell mixing experiments

\begin{tabular}{|c|c|c|c|c|c|}
\hline \multirow[b]{2}{*}{ Diagnosis } & \multirow[b]{2}{*}{$(n)$} & & \multicolumn{3}{|l|}{$C P M \pm S E M$} \\
\hline & & & $0.5^{*}$ & $I^{*}$ & $2^{*}$ \\
\hline \multirow[t]{2}{*}{ Controls } & (29) & Expected & $116018 \pm 9517$ & $145208 \pm 10676$ & $188571 \pm 11710$ \\
\hline & & Observed & $147262 \pm 12787$ & $164731 \pm 12433$ & $167395 \pm 10033$ \\
\hline \multirow[t]{2}{*}{ IBD } & (28) & Expected & $171726 \pm 13686$ & $208688 \pm 17479$ & $245992 \pm 19763$ \\
\hline & & Observed & $166064 \pm 13567$ & $170842 \pm 11653$ & $127521 \pm 8124$ \\
\hline
\end{tabular}

${ }^{*}$ LPL/PBL ratio.

matory bowel disease mucosa. To further evaluate this phenomenon, parallel experiments were designed to investigate dependence on cell proliferation.

Inhibition of proliferation by mitomycin $\mathrm{C}$ and $\mathrm{x}$-ray treatment augmented the enhancing effect of control lamina propria lymphocytes and practically abolished the suppressor effect of inflammatory bowel disease lamina propria lymphocytes (Table 4). The utilised dose of 1500 rads is known to profoundly affect $\mathrm{T}$ cell proliferation, suggesting that the suppressor activity displayed by intestinal mononuclear cells may be primarily dependent on proliferating thymus-derived cells.

Proliferative responses observed in our mixed cultures are certainly the result of interactions between one cell population and the other while replicating in response to phytohaemagglutinin. As the suppressor effect of lamina propria lymphocytes

Table 3 Effect of disease, anatomical origin, and immunosuppressive therapy on the variation of the $P H A$ induced proliferative response in cell mixing experiments*

\begin{tabular}{lcccc}
\hline & \multicolumn{4}{c}{$L P L / P B L$ ratio } \\
\cline { 3 - 5 } Groups & $(n)$ & $0 \cdot 5$ & 1 & 2 \\
\hline Controls & $(29)$ & $28 \pm 5$ & $16 \pm 6$ & $-5 \pm 5$ \\
IBD & $(28)$ & $2 \pm 5$ & $-9 \pm 6$ & $-38 \pm 6$ \\
p & & $<0 \cdot 001$ & $<0 \cdot 005$ & $<0 \cdot 001$ \\
Control LBt & $(22)$ & $28 \pm 6$ & $23 \pm 7$ & $-4 \pm 6$ \\
Control SB $\ddagger$ & $(7)$ & $29 \pm 8$ & $5 \pm 10$ & $-9 \pm 7$ \\
p & & NS§ & $<0 \cdot 05$ & NS \\
IBD LB & $(14)$ & $4 \pm 5$ & $-6 \pm 6$ & $-33 \pm 7$ \\
IBD SB & $(14)$ & $1 \pm 10$ & $-11 \pm 9$ & $-43 \pm 9$ \\
p & & NS & NS & NS \\
UC & $(10)$ & $5 \pm 8$ & $-8 \pm 7$ & $-37 \pm 9$ \\
CD & $(18)$ & $1 \pm 8$ & $-9 \pm 8$ & $-38 \pm 7$ \\
p & & NS & NS & NS \\
Steroid (+) & $(17)$ & $0 \pm 7$ & $-7 \pm 8$ & $-32 \pm 8$ \\
Steroid (-) & $(11)$ & $6 \pm 9$ & $-13 \pm 7$ & $-46 \pm 6$ \\
p & & NS & NS & NS \\
\hline
\end{tabular}

* Numbers represent percentage of variation.

† Large bowel.

$\ddagger$ Small bowel.

§ Not significant. is proliferation dependent, the degree of proliferation of both peripheral blood lymphocytes and lamina propria lymphocytes cultured alone in the presence of mitogen could bear a relationship to the observed variation of the expected response and be relevant to enhancing or suppressor effects. Therefore, we correlated the counts per minute derived from mitogen stimulated peripheral blood lymphocytes and lamina propria lymphocytes at all cell concentrations with the percentage of variation observed at each ratio by linear regression analysis. When the control cell mixing experiments were studied, no correlation was found in any cell concentration or ratio. To the contrary, in the inflammatory bowel disease group, a negative correlation was observed between the suppression of the expected response and the degree of mitogen

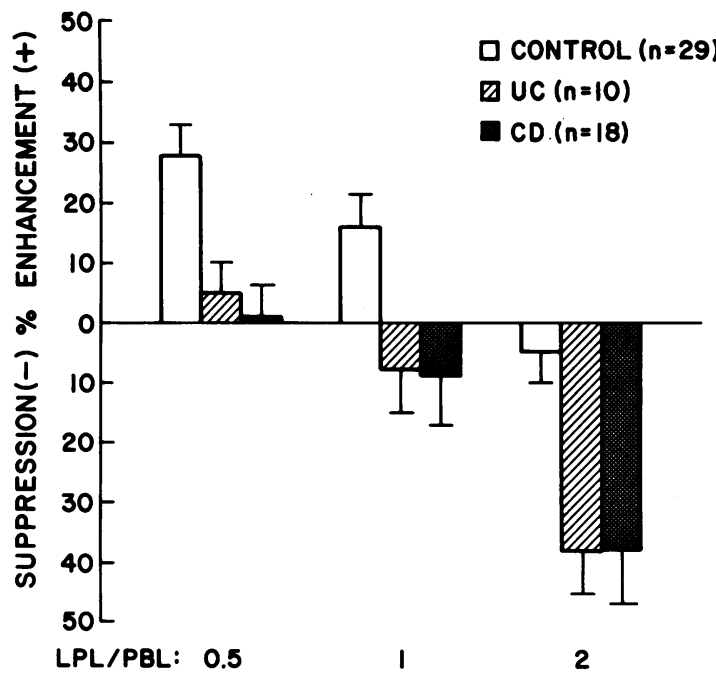

Figure Percentage of variation from expected proliferative response in cell mixing experiments. Control and inflammatory bowel disease peripheral blood lymphocytes were mixed with autologous lamina propria lymphocytes at different cell ratios and cultured for 72 hours in the presence of phytohaemagglutinin. 
Table 4 Effect of mitomycin C treatment and irradiation of LPL on the percentage of variation in cell mixing experiments

\begin{tabular}{|c|c|c|c|c|c|c|c|c|c|}
\hline & \multicolumn{9}{|c|}{ Treatment of $L P L$} \\
\hline & \multicolumn{3}{|l|}{ None } & \multicolumn{3}{|c|}{ Mitomycin C } & \multicolumn{3}{|c|}{1500 rads } \\
\hline & $0.5^{*}$ & $I^{*}$ & $2^{*}$ & 0.5 & 1 & 2 & 0.5 & 1 & 2 \\
\hline CA & 38 & 48 & 54 & 19 & 24 & 25 & 16 & 15 & 15 \\
\hline $\mathrm{CA}$ & 55 & -12 & 6 & 127 & 156 & 216 & 148 & 192 & 235 \\
\hline $\mathrm{CA}$ & 3 & 1 & -49 & 31 & 37 & 30) & 52 & 49 & 41 \\
\hline $\mathrm{CA}$ & 33 & -49 & -12 & 20 & 25 & 12 & 44 & 46 & 11 \\
\hline Mcan $\pm S E$ & $38 \pm 10$ & $1 \pm 16$ & $-7 \pm 18$ & $49 \pm 26$ & $60 \pm 32$ & $71 \pm 48$ & $65 \pm 29$ & $75 \pm 39$ & $75 \pm 53$ \\
\hline $\mathrm{CD}$ & 28 & -9 & -75 & 58 & 50 & 49 & 72 & 34 & -64 \\
\hline $\mathrm{CD}$ & 34 & 1 & -33 & 11 & -1 & -8 & 38 & 27 & 13 \\
\hline $\mathrm{CD}$ & -60 & -75 & -84 & 2 & -16 & 40 & -4 & -60 & -70 \\
\hline $\mathrm{CD}$ & 42 & 29 & 3 & 33 & 74 & 73 & 113 & 148 & 40 \\
\hline $\mathrm{CD}$ & 13 & 27 & -2 & 1 & 5 & 23 & 30 & 38 & 43 \\
\hline UC & 1 & -44 & -67 & 36 & 31 & -9 & 22 & 19 & -12 \\
\hline UC & 41 & -7 & -71 & -20 & -18 & -48 & 27 & 37 & -13 \\
\hline Mean $\pm \mathrm{SE}$ & $14 \pm 13$ & $-11 \pm 14$ & $-47 \pm 14$ & $17 \pm 10$ & $18 \pm 14$ & $17 \pm 15$ & $42 \pm 14$ & $34 \pm 23$ & $-9 \pm 17$ \\
\hline
\end{tabular}

* LPL/PBL ratio.

induced proliferation of peripheral blood lymphocytes and lamina propria lymphocytes. At lamina propria lymphocytes/peripheral blood lymphocytes ratio of two, the correlation was $r=-0.634$ $(\mathrm{p}<0.001)$ and $\mathrm{r}=-0.647 \cdot(\mathrm{p}<0.001)$ for the counts per minute of the peripheral blood lymphocytes and lamina propria lymphocytes, respectively.

\section{CONTROLS FOR CROWDING EFFECT, PHA DOSE,} AND CELL VIABILITY

When irradiated peripheral blood lymphocytes were added to a fixed number of autologous peripheral blood lymphocytes in the same proportions used in the cell mixing experiments, enhancement of the final proliferative response was observed $(32 \pm 17$, $25 \pm 12$, and $8 \pm 10$, respectively for irradiated peripheral blood lymphocytes/peripheral blood lymphocytes ratio of $0.5,1$, and 2 ). Additionally, as pointed out previously, mitomycin $\mathrm{C}$ and $\mathrm{x}$-ray treatments of inflammatory bowel disease lamina propria lymphocytes, which prevent proliferation but do not alter the total number of cells in culture, resulted in abrogation of the inhibition of the expected response. Both experiments eliminate the possibility that the suppressor effect observed in cell mixtures is secondary to non-specific crowding effect.

Doubling the amount of phytohaemagglutinin present in the mixed cell cultures did not result in enhancement of the total proliferation at any lamina propria lymphocytes/peripheral blood lymphocytes ratio (Table 5). On the contrary, in both control and inflammatory bowel disease cells, a tendency toward lower counts per minute values was observed, confirming that the amount of the mitogen was indeed at an optimal stimulatory level and that the suppressor effect observed with inflammatory bowel disease lamina propria lymphocytes was not secondary to lack of available phytohaemagglutinin for maximal proliferation.

Finally, when measured by trypan blue staining, the viability of the cells (in the presence or absence of phytohaemagglutinin) was similar in the control and inflammatory bowel disease mixing experiments and did not correlate with the percentage of enhancement or suppression of the response. As illustrated in Table 6, at any cell ratio, viabilities lower, equal to, or higher than the expected values were found associated with enhancement as well as

Table 5 Effect of increased PHA concentration on the proliferative response in cell mixing experiments

\begin{tabular}{|c|c|c|c|c|c|c|}
\hline \multirow[b]{3}{*}{ Diagnosis } & \multirow{3}{*}{$\begin{array}{l}\text { Cell } \\
\text { mixtures }\end{array}$} & \multirow{3}{*}{$\frac{L P L}{P B L}$} & \multicolumn{4}{|c|}{ PHA concentrations } \\
\hline & & & \multicolumn{2}{|l|}{$10 \mu \mathrm{l} / \mathrm{ml}$} & \multicolumn{2}{|c|}{$20 \mu l / m l$} \\
\hline & & & $C P M$ & $\%^{*}$ & $C P M$ & $\%$ \\
\hline \multirow[t]{3}{*}{ CA } & $\mathrm{PBL}+\mathrm{LPL}$ & 0.5 & 104628 & 3 & 82190 & -19 \\
\hline & & 1 & 138967 & 6 & 120807 & -8 \\
\hline & & 2 & 132876 & -26 & 136566 & -24 \\
\hline \multirow[t]{3}{*}{ UC } & $\mathrm{PBL}+\mathrm{LPL}$ & 0.5 & 123744 & 12 & 109446 & -1 \\
\hline & . & 1 & 136974 & 3 & 124785 & -6 \\
\hline & & 2 & 161206 & -13 & 154396 & -17 \\
\hline
\end{tabular}

* Variation from expected response. 
Table 6 Comparative evaluation of cell viability* with the percentage of variation in cell mixing experiments

\begin{tabular}{|c|c|c|c|c|c|c|c|c|c|c|}
\hline \multirow[b]{2}{*}{ Diagnosis } & \multirow{2}{*}{$\frac{P B L}{0.5+}$} & \multicolumn{3}{|l|}{$L P L$} & \multicolumn{6}{|c|}{$P B L+L P L$} \\
\hline & & $0 \cdot 25 t$ & $0.5+$ & $1+$ & $0.5 \ddagger$ & $\% \S$ & $1 \neq$ & $\%$ & $2 \ddagger$ & $\%$ \\
\hline CA & 82 & 43 & 45 & 24 & $57(62)$ & 24 & $37(63)$ & 14 & $52(53)$ & 0 \\
\hline Diverticulosis & 64 & 62 & 59 & 42 & $52(63)$ & 34 & $50(61)$ & 45 & $23(53)$ & -18 \\
\hline CD & 74 & 45 & 46 & 43 & $66(60)$ & -19 & $64(60)$ & -25 & $64(59)$ & -37 \\
\hline UC & 91 & 33 & 69 & 48 & $59(62)$ & 14 & $61(80)$ & 12 & $65(69)$ & -27 \\
\hline UC & 82 & 44 & 64 & 73 & $68(63)$ & -11 & $75(76)$ & -41 & $69(77)$ & -66 \\
\hline
\end{tabular}

* Determined as percentage of trypan blue excluding cells; number in parentheses indicates expected viability, calculated by averaging the viabilities of the PBL and LPL cultured alone.

+ Concentration $\times 10^{6} / \mathrm{ml}$

$\ddagger$ LPL/PBL ratio.

$\S$ Variation from expected response.

suppressor effect. This makes the killing of one cell population by the other unlikely, and rules out the possibility that the drop in proliferation seen in the inflammatory bowel disease cultures is a consequence of an excessive cell death rate.

\section{Discussion}

The present study provides evidence that human intestinal mucosa contains mononuclear cells that can exert an immunoregulatory effect upon autologous peripheral blood lymphocytes that are responding to a proliferative stimulus. Additionally, it shows that helper and suppressor effects are dependent on lamina propria lymphocytes concentration and on the presence or absence of inflammatory bowel disease in the intestinal segments from which the cells were derived.

Immunoregulatory cells, with helper or suppressor activity, have been studied in a variety of disease states. ${ }^{16}$ In inflammatory bowel disease, suppressor cell activity has been investigated using peripheral blood lymphocytes. Hodgson et $a l^{17}$ and Knapp et al ${ }^{18}$ have described decreased or absent concanavalin A (Con-A) induced suppressor cell function in active inflammatory bowel disease patients. In contrast, Elson et al ${ }^{19}$ have described an increased suppressor cell activity in Crohn's disease, mediated by 'covert' suppressor $\mathrm{T}$ cells, whose function was uncovered only after procedures used to obtain highly purified $\mathrm{T}$ cell populations. Imbalances of $\mathrm{T} \mu$ (helper) and $\mathrm{T} \gamma$ (suppressor) cells have also been investigated. Victorino and Hodgson reported a marked decrease of $\mathrm{T} \mu$ cells in inflammatory bowel disease ${ }^{20}$ while Pena et al found both subsets decreased in Crohn's disease. ${ }^{21}$

In considering these apparently discordant results, it must be remembered that suppressor cell systems are heterogeneous, ${ }^{22} 23$ different assay systems do not measure the same suppressor population and each method may provide different results in studies of the same subjects. ${ }^{24}$ Furthermore, when the disease is localised to a specific organ, as is the case of ulcerative colitis and Crohn's disease, immune abnormalities detected in the periphery may not reflect phenomena relevant to the pathogenesis of the intestinal inflammatory process.

Limited information is available on suppressor cell function of human intestinal mucosal mononuclear cells. Suppressor activity can be induced by stimulation of lamina propria lymphocytes with Con-A but no significant differences have been detected between control and inflammatory bowel disease lymphocytes ${ }^{3}$ although $\mathrm{T} \gamma$ cells have been described as decreased in inflammatory bowel disease lamina propria lymphocytes. ${ }^{25}$ Our data provide further evidence for the presence of suppressor cell activity at the intestinal level and show marked differences between control and diseased mucosa. Our results are in apparent disagreement with a recent report of Goodacre and Bienenstock. ${ }^{14}$ These authors, using a mechanical dissociation method to obtain intestinal mucosa mononuclear cells, reported decreased suppressor cell activity in the intestinal mucosa of patients with Crohn's disease. It has been shown that significant differences exist in the functional characteristics of enzymatically $v s$ mechanically isolated cells. ${ }^{26}$ The latter, in addition, do contain significant amounts of intraepithelial lymphocytes (IEL) which are absent from cell suspensions prepared by enzymatic treatment. ${ }^{1}$ Analysis with monoclonal antibodies has shown that intraepithelial lymphocytes and lamina propria lymphocytes display different phenotypes on their surfaces. Intraepithelial lymphocytes are almost entirely OKT8 positive (suppressor) cells, while lamina propria lymphocytes are predominantly OKT4 (helper) cells. ${ }^{27}$ The degree of inflammation and anatomical integrity may alter the 
relative proportions of intraepithelial lymphocytes and lamina propria lymphocytes in inflammatory bowel disease specimens and it is possible that mixing peripheral blood lymphocytes with intraepithelial lymphocytes and lamina propria lymphocytes or with lamina propria lymphocytes alone may produce different results.

Although the suppressor activity we detected is at least partially phytohaemagglutinin induced ${ }^{28}$ it is also true that helper or suppressor effects may be obtained by varying the cellular concentrations of the lymphocytes exposed to this mitogen. ${ }^{29}$ As lamina propria lymphocytes from inflammatory bowel disease and non-inflammatory bowel disease specimens are obtained under identical circumstances, have similar numbers of $T$ and $B$ cells and macrophages, and the cell mixing experiments are strictly autologous, the most likely explanation for the encountered differences is that ulcerative colitis and Crohn's disease lamina propria lymphocytes indeed possess cell subsets that are functionally different from those present in histologically normal, non-inflammatory bowel disease intestinal mucosa.

It is not surprising that inflamed mucosa might have different cell populations as compared with histologically normal control. In experimentally induced colitis, both number and function of isolated $\mathrm{T}$ cells are markedly altered as compared with controls. ${ }^{30}$ Furthermore, lymphocyte migration patterns are drastically altered in chronic inflammatory states. ${ }^{31} 32$ This creates conditions for mixing of immune competent cells from peripheral and target organ areas, therefore our in vitro cell mixing experiments may mimic an actual in vivo phenomenon.

The enhanced suppressor cell activity displayed by ulcerative colitis and Crohn's disease lamina propria lymphocytes may represent either a primary or a secondary phenomenon and this remains to be determined. Viral infections are known to activate suppressor cells. ${ }^{33}$ This is particularly relevant in inflammatory bowel disease, where latent viruses $^{3435}$ could be responsible for a persistently high suppressor cell activity at the intestinal level. Other chronic infections have also been associated with enhanced suppressor activity at the systemic level, ${ }^{23}$ as well as at an organ level. ${ }^{36}$ An excessive suppressor cell function has been associated with impairment of cell-mediated immunity. ${ }^{37} 38$ This may indeed occur at the intestinal level in inflammatory bowel disease, perhaps explaining the chronicity of the local inflammatory process and the occurrence of relapses.

The enhanced suppressor cell activity we found in inflammatory bowel disease mucosa could be expressed to down-regulate an exaggerated inflammatory process and therefore have potential beneficial effects. Conversely, it could suppress a physiological immune response and thus prevent an attempt to compensate for an increased enteric loss of mononuclear cells. ${ }^{39}$ Such phenomena are likely to significantly alter the immune status of the patients. For example, during a flare-up an enhanced intestinal loss of lymphocytes could cause shifting of lymphoid cells to the target organ. ${ }^{31} \mathrm{On}$ the other hand, the release of intestinal lymphocytes with enhanced suppressor activity into the general circulation could cause impairment of systemic immunity. Previously reported inconsistencies encountered in the measurements of the immune status of inflammatory bowel disease patients, such as the degree of peripheral blood lymphocytes response to phytohaemagglutinin, ${ }^{40}{ }^{4}$ could perhaps be explained.

Finally, it should be pointed out that this study does not show if the suppressor cell activity displayed by inflammatory bowel disease lamina propria lymphocytes is mediated by direct cell to cell interaction or by soluble factors, such as prostaglandins (PG) or interferon (IFN). Prostaglandin $E_{2}$ is known to be significantly raised in ulcerative colitis mucosa ${ }^{42}$ and isolated Crohn's disease lamina propria lymphocytes apparently synthesise increased amounts of prostaglandin $\mathrm{E}_{2}$ in vitro, ${ }^{43}$ which has pronounced immunosuppressive effects. ${ }^{44}$ Similarly, interferon, produced during practically all immune processes, ${ }^{45}$ is also known to markedly suppress the proliferative response to phytohaemagglutinin. ${ }^{46}$ The study of soluble factors as mediators of suppressor cell activity at the gut mucosal level has great practical importance, in view of potential therapeutic implications, and it is currently under investigation in our laboratory.

This work was supported in part by a grant (CRP 919) from the Clinical Research Projects Committee of the Cleveland Clinic Foundation. The authors acknowledge the cooperation of the members of the Department of Colon and Rectal Surgery and Surgical Pathology for supplying the surgical specimens.

This paper was presented in part at the 1981 Annual Meeting of the American Gastroenterological Association in New York City, NY, USA.

\section{References}

1 Bull DM, Bookman MA. Isolation and functional characterization of human intestinal mucosal lymphoid cells. J Clin Invest 1977; 59: 966-74.

2 Goodacre R, Davidson R, Singhal D et al. Morpho- 
logical and functional characteristics of human intestinal cells isolated by a mechanical technique Gastroenterology 1979; 76: 300-8.

3 Fiocchi C, Battisto JR, Farmer RG. Gut mucosal lymphocytes in inflammatory bowel disease. Isolation and preliminary functional characterization. Dig Dis Sci 1979; 24: 705-17.

4 Bookman MA, Bull DM. Characteristics of isolated intestinal mucosal lymphoid cells in inflammatory bowel disease. Gastroenterology 1979; 77: 503-10.

5 Bartnick W, Re Mine SG, Chiba M et al. Isolation and characterization of colonic intraepithelial and lamina propria lymphocytes. Gastroenterology 1980; 78: 97985.

6 MacDermott RP, Franklin GO, Jenkins KM et al. Human intestinal mononuclear cells. I. Investigation of antibody-dependent, lectin-induced and spontaneous cell-mediated cytotoxic capabilities. Gastroenterology 1980; 78: 47-56.

7 MacDermott RP, Bragdon MJ, Jenkins KM et al. Human intestinal mononuclear cells. II. Demonstration of naturally occurring subclasses of $T$ cells which respond in the allogeneic mixed leukocyte reaction but do not effect cell-mediated lympholysis. Gastroenterology 1981; 80: 748-57.

8 Fiocchi C. Battisto JR, Farmer RG. Studies on isolated gut mucosal lymphocytes in inflammatory bowel disease. Detection of activated $\mathrm{T}$ cells and enhanced proliferation to Staphylococcus aureus and lipopolysaccharides. Dig Dis Sci 1981; 26: 728-36.

9 MacDermott RP. Human intestinal mononuclear cells isolated from normal and inflammatory bowel disease specimens are a functionally unique lymphoid population. In: Pena AS, Weterman IT, Booth CC, Strober W, eds. Recent advances in Crohn's disease. The Hague: Martinus Nijhoff Publishers, 1981: 439-44.

10 Chiba M, Shorter RG, Thayer WR et al. K-cell activity in lamina propria lymphocytes from human colon. Dig Dis Sci 1979; 24: 817-22.

11 Chiba M, Bartnik W, Re Mine SG et al. Human colonic intraepithelial and lamina propria lymphocytes: cytotoxicity in vitro and the potential effects of the isolation method of their functional properties. Gut 1981; 22: 177-86.

12 Falchuk ZM, Barnhard E, Machado I. Human colonic mononuclear cells: studies of cytotoxic function. Gut 1981; 22: 290-4.

13 Reid RH. Intestinal lamina propria mononuclear cells suppress the splenic lymphocyte phytohemagglutinin (PHA) response. (Abstract.) Gastroenterology 1979; 76: $1225 \mathrm{~A}$.

14 Goodacre R, Bienenstock J. Reduced suppressor cell activity in intestinal lymphocytes from patients with Crohn's disease. Gastroenterology 1982; 82: 653-8.

15 Kung PC, Goldstein G, Reinherz EL et al. Monoclonal antibodies defining distinctive human $\mathrm{T}$ cell surface antigens. Science 1979; 206: 347-9.

16 Reinherz EL, Schlossman SF. Regulation of the immune response. Inducer and suppressor $\mathrm{T}$ lymphocytes subsets in human beings. $N$ Engl J Med 1980; 303: 370-3.

17 Hodgson HJF, Wands JR, Isselbacher KJ. Decreased suppressor cell activity in inflammatory bowel disease. Clin Exp Immunol 1978; 32: 451-8.

18 Knapp W, Smolen JS, Lanzer G et al. Con-A induced suppressor cell activity in IBD and other inflammatory conditions. In: Pena AS, Weterman IT, Booth CC, Strober W, eds. Recent Advances in Crohn's disease. The Hague: Martinus Nijhoff Publishers, 1981: 380-8.

19 Elson CO, Graeff AS, James SP et al. Covert suppressor T cells in Crohn's disease. Gastroenterology 1980; 80: 1513-21.

20 Victorino RMM, Hodgson HJF. Alteration in T lymphocytes subpopulations in inflammatory bowel disease. Clin Exp Immunol 1980; 41: 156-65.

21 Pena AS, Cnossen J, Damsteeg MG et al. T cell subpopulations in Crohn's disease. In: Pena AS, Weterman IT, Booth CC, Strober W, eds. Recent advances in Crohn's disease. The Hague: Martinus Nijhoff Publishers, 1981: 403-6.

22 Lobo PI, Spencer CE. Inhibition of humoral and cell-mediated immune responses in man by distinct suppressor cell systems. J Clin Invest 1979; 63: 1157-63.

23 Stobo JD, Paul S, Van Scoy RE et al. Suppressor thymus-derived lymphocytes in fungal infection. J Clin Invest 1976; 57: 319-28.

24 Coovadia HM, McKay IR, d'Apice AJ. Suppressor cells assayed by three different methods in patients with chronic active hepatitis and systemic lupus erythematosus. Clin Immunol Immunopathol 1981; 18: 268-75.

25 Re Mine SG, Bartnik W, Bahn RC, Shorter RG. Further characterization of lymphocytes from human colonic lamina propria: identification of $\mathrm{T}_{\mathrm{G}}$ cells. Clin Exp Immunol 1981; 46: 294-300.

26 Bland PW, Richens ER, Britton DC, Lloyd J. Isolation and purification of human large bowel lymphoid cells: effect of separation technique on functional characteristics. Gut 1979; 20: 1037-46.

27 Janossy G, Tidman N, Selby WS et al. Human T lymphocytes of inducer and suppressor type occupy different microenvironments. Nature 1980; 288: 81-4.

28 Kurnick JT, Bell C, Grey HM. PHA-induced activation of suppressor cells in normal human peripheral blood lymphocytes. Scand J Immunol 1976; 5: 771-8.

29 Farrant J, Knight SC. Help and suppression by lymphoid cells as a function of cell concentrations. Proc Natl Acad Sci 1979; 76: 3507-10.

30 Glick ME, Falchuk ZM. Dinitrocholorobenzene-induced colitis in the guinea pig: studies of colonic lamina propria lymphocytes. Gut 1981; 22: 120-5.

31 Chin W, Hay JB. A comparison of lymphocyte migration through intestinal lymph nodes, subcutaneous lymph nodes and chronic inflammatory sites of sheep. Gastroenterology 1980; 79: 1231-42.

32 Rose ML, Parrott DMV, Bruce RG. Migration of lymphoblasts to the small intestine. II. Divergent migration of mesenteric and peripheral immunoblasts to sites of inflammation in the mouse. Cell Immunol 1979; 27: 36-46.

33 Tosato G, Magrath I, Koski I et al. Activation of suppressor $T$ cells during Epstein-Barr-virus induced 
infectious mononucleosis. $N$ Engl J Med 1979; 301: 1133-7.

34 Gitnick GL, Arthur MH, Shibata I. Cultivation of viral agents from Crohn's disease. Lancet 1976; 2: 215-9.

35 Gitnick GL, Rosen VJ, Arthur MH et al. Evidence for the isolation of a new virus from ulcerative colitis patients. Comparison with virus derived from Crohn's disease. Dig Dis Sci 1979; 24: 609-19.

36 Ellner JJ, Olds GR, Kamel R et al. Suppressor splenic T lymphocytes in human hepatosplenic Schistosomiasis mansoni. J Immunol 1980; 125: 308-12.

37 Hilliger SM, Herzig JP. Impaired cell-mediated immunity in Hodgkin's disease mediated by suppressor lymphocytes and monocytes. J Clin Invest 1978; 61: 1620-7.

38 Reinherz EL, Parkman R, Rappaport J et al. Aberration of suppressor T cells in human graft-versushost disease. $N$ Engl J Med 1979; 300: 1061-8.

39 Douglas AP, Weetman AP, Haggith JW. The distribution and enteric loss of ${ }^{51} \mathrm{Cr}$-labelled lymphocyte in normal subjects and in patients with coeliac disease and other disorders of the small intestine. Digestion 1976; 14: $29-43$.
40 Sachar DB, Taub RN, Brown SM et al. Impaired lymphocyte responsiveness in inflammatory bowel disease. Gastroenterology 1973; 64: 203-9.

41 Bird AG, Britton S. No evidence for decreased lymphocyte reactivity in Crohn's disease. Gastroenterology 1974; 67: 926-32.

42 Rampton DS, Sladen GE, Youlten LJF. Rectal mucosal prostaglandin $E_{2}$ activity and its relation to disease activity, electropotential difference and treatment in ulcerative colitis. Gut 1980; 21: 591-6.

43 Rachmilewitz D, Zifroni A, Ligumsky $\mathrm{M}$ et al. Enhanced prostanoids synthesis by cultured peripheral blood mononuclear and intestinal lymphoid cells in Crohn's disease. (Abstract.) Gastroenterology 1981; 80: 1256A.

44 Goodwin JS, Webb DR. Regulation of the immune response by prostaglandins. Clin Immunol Immunopathol 1980; 15: 106-22.

45 Bloom BR. Interferon and the immune system. Nature 1980; 284: 593-5.

46 Heron I, Berg K, Cantell K. Regulatory effect of interferon on $\mathrm{T}$ cells in vitro. $J$ Immunol 1976; 117: 1370-3. 